\title{
Does Marx Need to Transform?
}

\author{
W. Paul Cockshott and Allin F. Cottrell*
}

Revised, May 1995

\section{Introduction}

Almost all of the voluminous literature on the Marxian 'transformation problem' is predicated on the assumption that, whether or not he succeeded, what Marx was trying to do in Part II of Capital, volume III-namely, derive a set of prices consistent with the equalisation of the rate of profit across all capitals - was correct. Those neo-Ricardians who argue that there is really no 'transformation' problem as such (on the grounds that labour values are theoretically redundant - see Steedman, 1977) most emphatically share this assumption.

A rare exception to this orthodoxy is Farjoun and Machover's Laws of Chaos (1983). Farjoun and Machover, like Steedman, conclude that there is really no transformation problem, but for a very different reason, namely that the assumption of a tendency toward the equalisation of the rate of profit is both empirically false and theoretically untenable. Rather, they claim, the predictions of the simple labour theory of value, as in Volume I of Capital, are in better accord with the facts.

Our aims in this paper are to explain this claim, to present some empirical data by means of which the claim may be assessed (based mainly on analysis of the UK input-output tables), and to offer some (tentative) thoughts on the economic mechanisms that might be responsible for generating the observed data. We should point out that if the transformation problem is conceived as a purely logical exercise - a matter of showing how

*Turing Institute, Glasgow, and Department of Economics, Wake Forest University, respectively. This paper was prepared for the conference on Karl Marx's third volume of 'Capital': 1894-1994, University of Bergamo, December 15-17, 1994, and published in R. Bellofiore (ed.) Marxian Economics: A Reappraisal, volume 2, Basingstoke and New York: Macmillan and St. Martin's, 1998. 
an aggregative labour theory of value can be reconciled with the assumption of an equalized rate of profit - then our paper has nothing to say about it. Our belief is that the transformation from labour values to prices of production was a live issue for Marx because he thought there really was a strong tendency for the rate of profit to be equalised, so that the simple labour theory of value would yield seriously counterfactual predictions. We will argue that Marx was wrong on this point.

We begin with a brief examination of the logic of the standard equalisedprofit assumption.

\section{The tendency towards an equalised rate of profit}

Supporters of the assumption of an equal rate of profit for the purposes of the theoretical analysis would surely admit that rates of profit, in any particular economy at any particular time, show quite a wide dispersion. Their claim is not that there actually exists a single rate of profit, but that there exists a definite tendency to produce equalisation, and that for theoretical purposes it is legitimate to assume that this tendency is fully realised.

But what exactly is the status of such a tendency? On this theory, should we expect to see the dispersion of rates of profit narrowing over time in actual capitalist economies? If that is the idea, it seems to be empirically false. Farjoun and Machover produce evidence that the empirical frequency distribution of profit rates is broadly stable over time, with no observable tendency to collapse towards degeneracy. The alternative is to claim that the tendency towards equalisation is something inherent in the process of competition among capitals, but that it is 'masked' by the continuous occurrence of external shocks or disturbances. This theory relies on a partitioning of the causes operating on the dispersion of profit rates. Internal to the logic of the system is a competitive process that drives towards equalisation, while the dispersion-enhancing disturbing factors are exogenous. What are the latter factors? If they were sunspots, hurricanes, earthquakes and so on, the theory would be coherent (but even so, if the net result of the endogenous equalisation process and the exogenous shock process is the maintenance of a roughly steady degree of dispersion, the equalised-rate assumption would not be very useful for analysis of real economies). But surely the most significant factors making for increased dispersion of profit rates are just as endogenous to the process of capitalist competition, or rivalry, as the equalizing factors: the development and application of new technologies; the development of new products; the exploitation of new markets or new 
sources of supply of labour or raw materials.

In the classical analysis - shared by Smith, Ricardo and Marx - the primary force working towards equalisation is the mobility of capital between sectors of the economy in response to profit-rate differentials. If industry $X$ is showing above-average profit, capital will move in, increasing the supply of the product and hence driving down both price and profit-rate. If Industry $Y$ shows below-average profit, capital will tend to exit the industry, reducing supply and hence raising price and profit-rate. This mechanism makes sense in itself ${ }^{1}$ but it represents only one aspect of capitalist competition, understood broadly as the restless search for the greatest possible profit. Admit the other aspects of inter-capitalist rivalry (alluded to above), and it becomes an empirical question whether competition produces (a) an actual tendency towards equalisation, (b) a tendency towards ever greater dispersion, or (c) a roughly stable probability distribution for the rate of profit. As we have noted, the available data favour conclusion (c).

Why, then, does the equalised-profit assumption exercise such a hold over theorists? It may be that there is a temptation to think of competition among productive capitals on the model of arbitrage in financial markets. But this model is very misleading. The equalisation of returns on financial assets comes about almost instantaneously via revaluation of securities, while the equalisation of returns on industrial capital is at best a very slow process, dependent upon on the rate of depreciation and the speed with which new production facilities can be financed, built, and brought into production. There is also the syndrome of looking for one's keys under the lamp post. Suppose the equalisation assumption is false - all the same, how else is one supposed to derive determinate theoretical results? If one assumes a non-equalised set of profit rates, how can one reach any conclusions? Indeed, will this not undermine the simple labour theory of value just as severely as it undermines the theory of prices of production? The problem here is the restriction of the search to determinate results: a stochastic version of the labour theory of value can manage quite well without an equalised profit rate, and still generate interesting and testable predictions regarding the 'laws of motion' of capitalism. Farjoun and Machover (1983) show how this can be so. In chapters 5 and 6 of their book they explain why it might be that prices tend to proportionality with labour content for broadly defined groups of commodities, in a context where the rate of profit

\footnotetext{
${ }^{1}$ Although it raises the question of the conditions required for such migration to produce stable convergence on an equalised rate of profit, on which topic see Steedman (1984), Duménil and Lévy (1993).
} 
is far from equalised, while in chapter 7 they offer an interesting discussion of the dynamic-historical 'law of decreasing labour-content'.

\section{The stochastic approach}

Farjoun and Machover make a distinction between the realm of production, where matters are relatively determinate, and the realm of price-formation and profits, where the 'anarchy of the market' prevails and the relevant magnitudes must be thought of as random variables. The search for the 'correct' determinate linkages between these variables is displaced by an analysis of the relevant probability distributions, their respective degrees of dispersion and their interconnections. In this spirit we offer below a list of the most important distributions to be examined in order to assess the relative merits of the simple labour theory of value and the theory of prices of production (either Marxian or Sraffian).

1. The distribution of ratios of market prices to labour values, $f(\psi)$, where $\psi=P / \Lambda$. $(P$ denotes market price and $\Lambda$ denotes embodied labour-time.)

2. The distribution of rates of profit, $f(r)$, where $r=S /(C+V)$. (As usual, $S, C$ and $V$ denote, respectively, surplus value, constant capital and variable capital.)

3. The distribution of ratios of market prices to prices of production, $f(\phi)$, where $\phi=P / \Pi$. ( $\Pi$ denotes prices of production.)

4. The distribution of organic composition of capital, $f(o)$, where $o=$ $C /(S+V)$.

5. The distribution of rates of surplus value, $f(s)$, where $s=S /(S+V)$.

A word on the definitions of these distributions. First of all, we should emphasise that the magnitudes $S, C$ and $V$ are all expressed in money terms. Thus while we refer to the ratio $S /(S+V)$ as the 'rate of surplus value' for the sake of brevity, it should properly be called the money-rate of surplus value. The only magnitude above whose dimension is labour-hours is $\Lambda$, the denominator of the price-value ratio. Conceptually, $f(r)$ is the probability density function such that $\int_{a}^{b} f(r) d r$ gives the fraction of the total social capital earning a rate of profit $a<r<b$ percent. Similarly, $\int_{a}^{b} f(o) d o$ gives the fraction of capital having an organic composition $a<o<b$, and 
$\int_{a}^{b} f(s) d s$ gives the fraction of capital displaying a rate of surplus value $a<s<b$. For the ratio of market price to value, $\int_{a}^{b} f(\psi) d \psi$ gives the fraction of the total social product (measured in embodied labour-time) exchanging for a price $a<\psi<b$ per unit of embodied labour; and $\int_{a}^{b} f(\phi) d \phi$ gives the fraction of the total product (measured in terms of its price of production) exchanging for an observed price $a<\phi<b$ per unit price of production.

Table 1 shows the respective predictions of the simple labour theory of value or LTV (understood as the claim that commodities exchange in proportion to the socially necessary labour time required to produce them) and the theory of prices of production or TPP (that is, the theory that prices are formed so as to ensure an equalised rate of profit), with regard to these distributions. In the table, 'narrow' indicates that the distribution in question ought, on the particular theory, to have a relatively small standard deviation (taken literally, the prediction in these cases is degeneracy of the distribution, but nobody expects to find that in practice). The entry 'wide' indicates that the theory places no restriction on the degree of dispersion of the distribution in question.

In principle, the simple LTV restricts only the distribution of price-tovalue ratios. Given the auxiliary assumption that the dispersion of wage rates across industries is relatively narrow, however, the LTV also predicts a narrow dispersion of money-rates of surplus value. A word of explanation here: suppose that the wage is uniform across industries, as are the intensity of labour, working hours, and average skill levels. (Or, somewhat less restrictively, suppose that the wage per hour of simple labour of average intensity is uniform across sectors, with skilled labour counting as a suitable multiple of simple.) In that case it is true by definition that the rate of surplus value in labour-time terms is uniform. Now, if prices are simply proportional to values, the money-rate of surplus value (which is what we are measuring) will also be uniform. Since we have built the assumption of a uniform wage (per hour of simple labour) into our measurements, by using the wage bill of each sector as a proxy for hours worked, we place the prediction 'narrow' against the money-rate of surplus value, $s$, in the LTV column.

The theory of prices of production restricts only the distributions of rates of profit and, correspondingly, the ratios of actual prices to prices of production. 
Table 1: Predictions of labour theory of value and theory of prices of production

\begin{tabular}{ccc} 
Distribution & LTV & TPP \\
\hline$\psi=P / \Lambda$ & narrow & wide \\
$r=S /(C+V)$ & wide & narrow \\
$\phi=P / \Pi$ & wide & narrow \\
$o=C /(S+V)$ & wide & wide \\
$s=S /(S+V)$ & narrow & wide \\
\hline
\end{tabular}

\section{The data}

We now turn to the empirical probability distributions for these variables. Our data are derived from the UK input-output tables for 1984 (Central Statistical Office, 1988). As mentioned above, $S, C$ and $V$ are all expressed in monetary terms. Values, $\Lambda$, and prices of production, $\Pi$, were calculated by an iterative procedure. The input-output tables give a single, discrete observation on $S, C, V, P, \Lambda$ and $\Pi$ for each sector of the economy. The statistics of interest (mean, standard deviation and coefficient of variation) were calculated from these discrete observations using appropriate weights. For instance, in calculating the standard deviation for $\psi=P / \Lambda$ the weight given to each sector is $w_{i}=\Lambda_{i} / \sum_{i} \Lambda_{i}$, while for the rate of profit the weight is $w_{i}=\left(C_{i}+V_{i}\right) / \sum_{i}\left(C_{i}+V_{i}\right)$. The graphs showing the shape of the various distributions were derived via the application of a convolution function to the discrete data. Let $\hat{x}_{i}, i=1, \ldots, n$ denote the discrete observations on some variable of interest, $x$, for each of the $n$ sectors in the input-output table. We compute the continuous pdf given by

$$
f(x)=\sum_{i=1}^{n} w_{i} N_{\hat{x}_{i}, \sigma_{c}}(x)
$$

where $N_{\mu, \sigma_{c}}(x)$ is the value of the normal pdf, with mean $\mu$ and standard deviation $\sigma_{c}$, at point $x$. The assumption here is that each of the sectoral observations in fact represents the mean of a normal distribution. (The rationale for this is that each sector represents the aggregation of many firms, producing a great variety of particular products. Within a given sector such as 'Oils and fats' it will not be the case that every firm has the same organic composition of capital, or every product the same ratio of price to value. We assume that the distribution of such variables within each 
sector is similar in shape to the distribution across the sectors, but centred on the observed sectoral mean.) The degree of smoothing of the resulting curve depends on the value chosen for $\sigma_{c}$, the standard deviation employed in the convolving function. (In the plots shown, $\sigma_{c}$ was set at one-fifth of the standard deviation of the relevant distribution as a whole.)

The UK tables comprise 101 sectors, five of which we excluded from our analysis (Agriculture, Extraction of oil and gas, Mineral oil processing, Gas, and Banking and finance). The rationale for excluding the first four of these sectors is that they exhibit strong rent effects. Ricardo and Marx were very clear on how rent produces a deviation from the simple labour theory of value, and the rent effect is not at issue between the labour theory of value and the theory of prices of production. The rent effect is most apparent in the case of oil and gas extraction. Figure ?? shows, for reference, the distribution of $\phi$, the ratio of market price to price of production, for all 101 sectors: the outlier to the right is the oil and gas sector. As regards the ratios of market prices to labour values, this induces a substantial secondround deviation for the oil processing and gas distribution sectors, since purchases from the oil and gas extraction sector account for approximately 50 percent and 30 percent, respectively, of the total input costs of these two sectors. In addition, the figure for income from employment in Agriculture is likely to understate substantially the labour used in that sector, due to the existence of family farms. Finally, the Banking and finance sector is excluded on the grounds that most of its receipts from the other sectors are composed of interest payments, rather than payments for goods or services that take labour to produce.

We should point out that due to the limitations of the available UK data, our figures for constant capital, $C$, are in flow rather than stock terms throughout. Correspondingly, our rates of profit, prices of production, and organic compositions, are all on a flow basis. We recognise that this constitutes a serious limitation of the present study, and we plan to calculate these variables on a stock basis, using data from the USA, in future work.

Two other details of our calculation methods may be noted: we evaluated the output of each sector at producer prices; and we counted the payment of interest to the banking sector as part of the surplus value in each sector.

Table 2 shows the summary statistics for the observed distributions of $o, r, s, \phi$ and $\psi$, ranked in order of coefficient of variation. Thus our measure of organic composition, has the greatest degree of dispersion and $\psi$, the ratio of market prices to values, has the least. Note that the rate of profit, $r$, has a somewhat higher coefficient of variation than the rate of surplus value, $s$, and the ratios of actual prices to prices of production are 


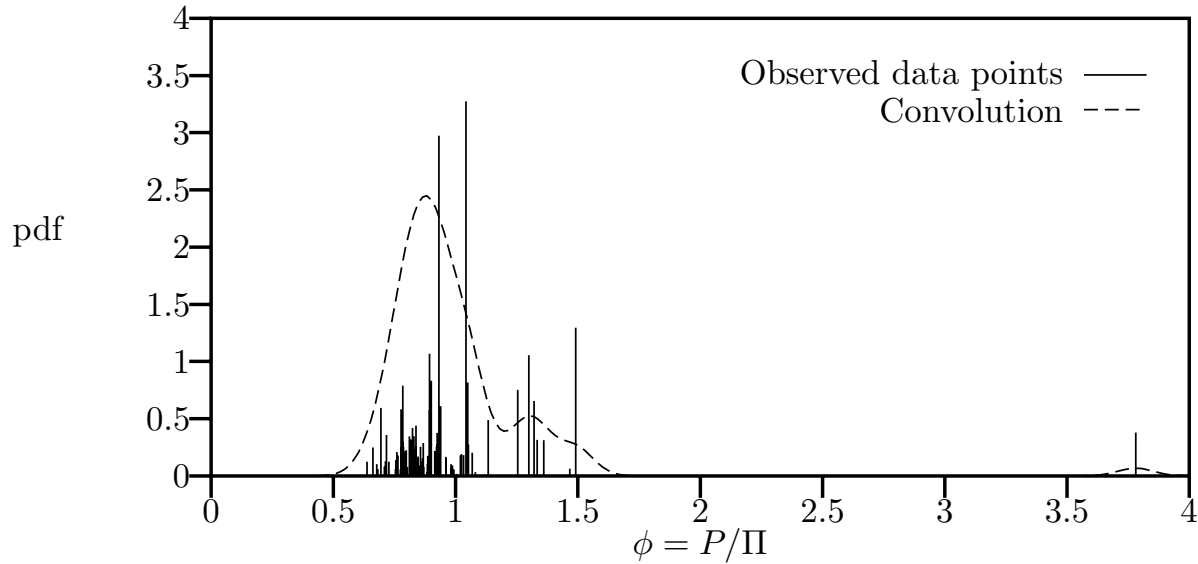

Figure 1: Ratios of actual prices to prices of production, 101 sectors

slightly more broadly dispersed than the ratios of actual prices to values.

Table 2: Summary statistics for empirical distributions

\begin{tabular}{cccc} 
Distribution & Mean & Std. Dev. & C. V. \\
\hline$o=C /(S+V)$ & 0.846 & 0.636 & 0.752 \\
$r=S /(C+V)$ & 0.211 & 0.129 & 0.608 \\
$s=S /(S+V)$ & 0.315 & 0.134 & 0.423 \\
$\phi=P / \Pi$ & 1.000 & 0.114 & 0.114 \\
$\psi=P / \Lambda$ & 1.000 & 0.104 & 0.104 \\
\hline
\end{tabular}

These findings are also illustrated by Figures ??, ?? and ??. Figure ?? shows both the sectoral data points and the convolved probability density function for the organic composition of capital. The outliers to the right are all sectors involved with food processing - Oils and fats, Sugar, Grain milling, and so on. These industries, it appears, take as their major input large quantities of agricultural commodities, and process them with relatively little labour input, per unit-value of raw materials. It may be noted, though, that even if these industries are left out of the calculation, the coefficient of variation for organic composition still exceeds that of any other variable under consideration. On the other hand, the great bulk of the pdf lies within the range 0.2 to 2.0 , which represents a considerably narrower 
distribution than is implicit in many of the examples drawn up by Sraffian theorists.

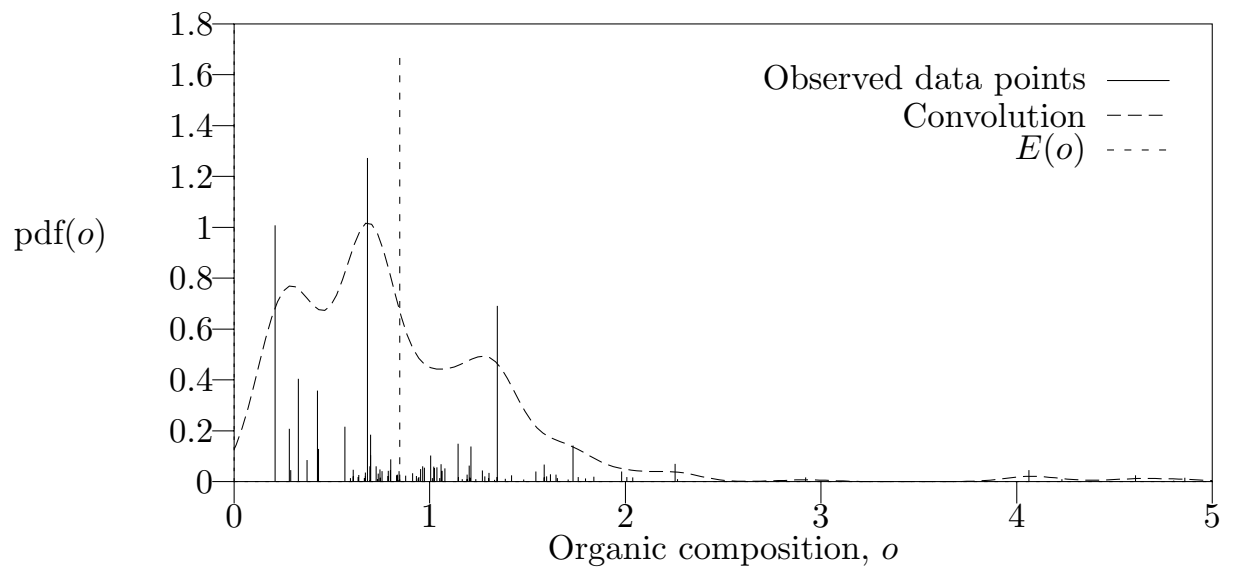

Figure 2: Empirical distribution of organic composition

Figure ?? shows the convolved density functions for both the rate of profit and the rate of surplus value. As can be seen, the distribution of the rate of profit is far from degenerate. Figure ?? shows the distributions for the ratios of actual prices to values, and of actual prices to prices of production. It is easily seen that the degree of dispersion is quite similar in the two cases. (Note that both of these distributions have a mean of unity by construction. In effect, we have chosen a unit of measurement of labour so as to satisfy Marx's stipulation that the sum of prices equals the sum of values.)

\section{Implications of the data}

Let us first consider the implications of the above data for the theory of prices of production. As we noted, the rate of profit is far from actual equalisation. On the other hand, the distribution of ratios of actual prices to prices of production is relatively tight. So can we say that the theory of prices of production holds as a reasonable approximation? Not really. There are some important anomalies in the data, from the point of view of this theory. Note that the ratio of market price to value can be be decomposed as follows: 


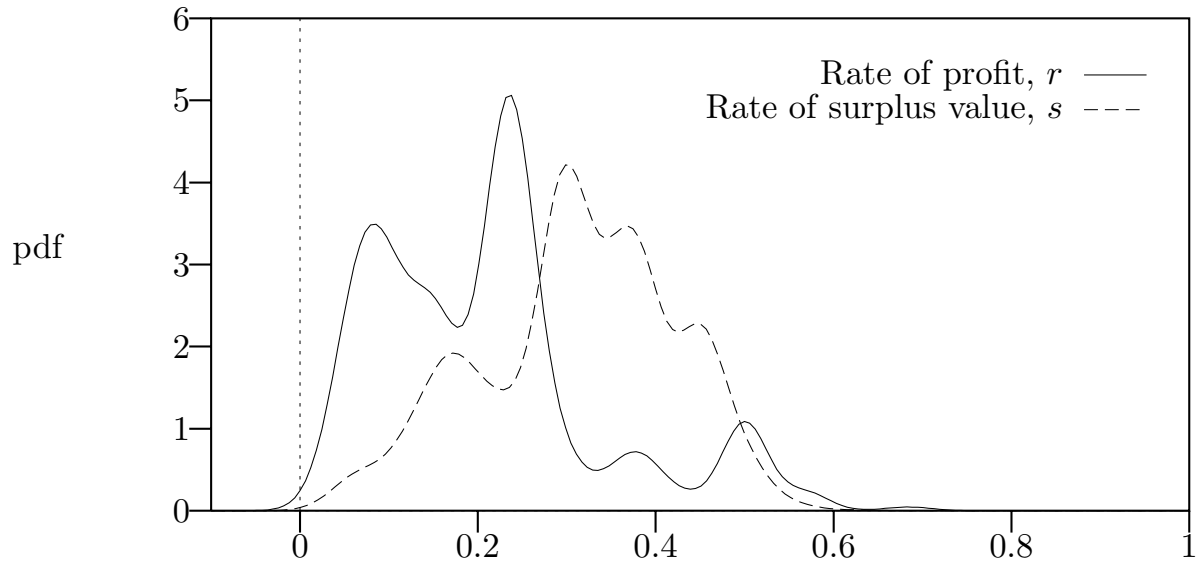

Figure 3: Distributions of rates of profit and of surplus value

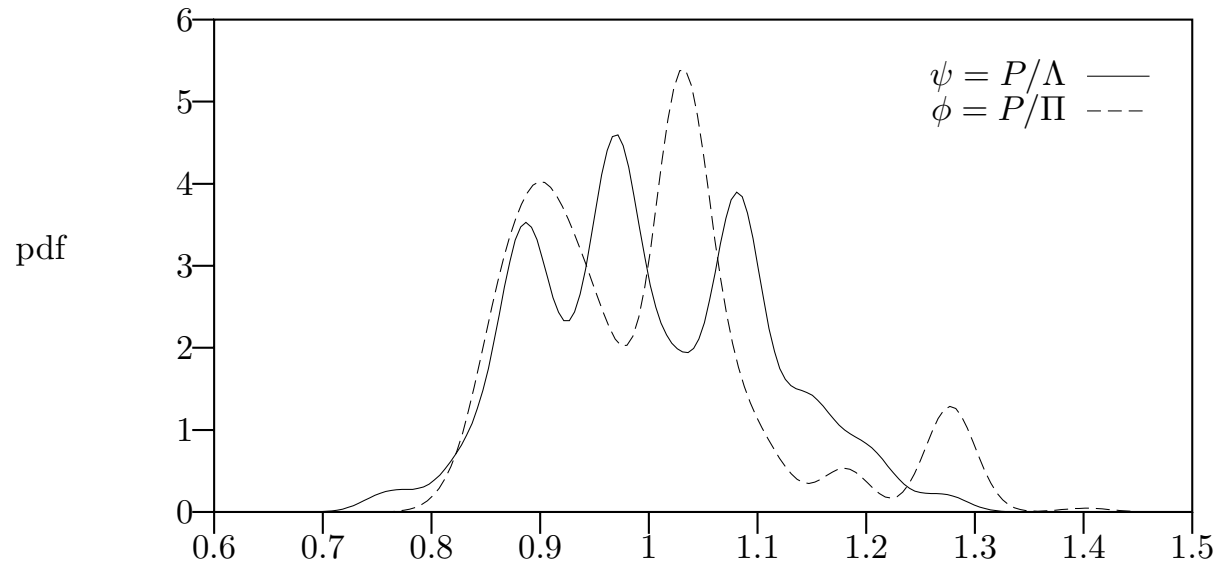

Figure 4: Ratios of actual prices to values, and to prices of production 


$$
\frac{P}{\Lambda}=\frac{P}{\Pi} \frac{\Pi}{\Lambda}
$$

In terms of logs, this can be re-written as

$$
\log (P)-\log (\Lambda)=(\log (P)-\log (\Pi))+(\log (\Pi)-\log (\Lambda)),
$$

which is to say that the deviation, in log terms, of price from value is the sum of (a) the deviation of price from price of production, and (b) the deviation of price of production from value. According to the theory of prices of production, these two elements ought to be independent of each other. Deviation (a) reflects the stochastic non-equalisation of the rate of profit, while deviation (b) reflects the dispersion of the organic composition of capital; and it is the whole point of this theory that prices ought to be formed so as to eliminate any systematic effect of differential organic composition on profit rates.

Now, if $x$ and $y$ are two independently distributed random variables, and if $z=x+y$, then $\operatorname{var}(z)=\operatorname{var}(x)+\operatorname{var}(y)$. The implication is that, provided the distribution of the organic composition is not degenerate - and it clearly is not, in the actual data - the standard deviation of $P / \Lambda$ ought to be greater than that of $P / \Pi$. But this is not the case. It must be, then, that the distribution of profit rates is not in fact independent of the distribution of the organic composition of capital, which is to say that the theory of prices of production, even under a stochastic interpretation, is false.

A closely related anomaly from the standpoint of the price of production theory is the fact that the rate of surplus value (which is on this theory not subject to any equalisation pressure) shows a smaller relative dispersion than the rate of profit.

A further perspective on these points is given by Table 3, which displays the correlation matrix for all of the variables under consideration. Note the negative correlation (statistically significant at the .005 level) between the rate of profit and the organic composition of capital. It is this negative correlation that explains how simple labour values are able to provide as good a fit to actual prices (actually, on our data, a slightly better fit) as prices of production. The close fit between prices and labour values is in line with the results of a series of regression analyses, including Shaikh (1984), Petrovic (1987), Ochoa (1989), Valle Baeza (1994) and Cockshott, Cottrell and Michaelson (1995).

To reinforce this point, Figure ?? shows the data points for organic composition and rate of profit, along with the fitted line from the regression 
Table 3: Correlation matrix

\begin{tabular}{crcccc}
\hline & \multicolumn{1}{c}{$o$} & $r$ & $s$ & $\phi$ & $\psi$ \\
$o=C /(S+V)$ & 1.000 & & & & \\
$r=S /(C+V)$ & -0.288 & 1.000 & & & \\
$s=S /(S+V)$ & 0.369 & 0.517 & 1.000 & & \\
$\phi=P / \Pi$ & -0.224 & 0.930 & 0.491 & 1.000 & \\
$\psi=P / \Lambda$ & 0.423 & 0.569 & 0.579 & 0.663 & 1.000 \\
\hline
\end{tabular}

Note: For a sample size of 96 , the 1 per cent critical value of the correlation coefficient, $\hat{\rho}$, is 0.262 .

of the rate of profit on the inverse of the organic composition (which, as one would expect on the basis of the simple labour theory of value, gives a better fit than a linear relationship). This is a striking result; we should, however, remind the reader that it should be regarded as provisional, given that both the rate of profit and organic composition are calculated here using the flow rather than the stock of constant capital.

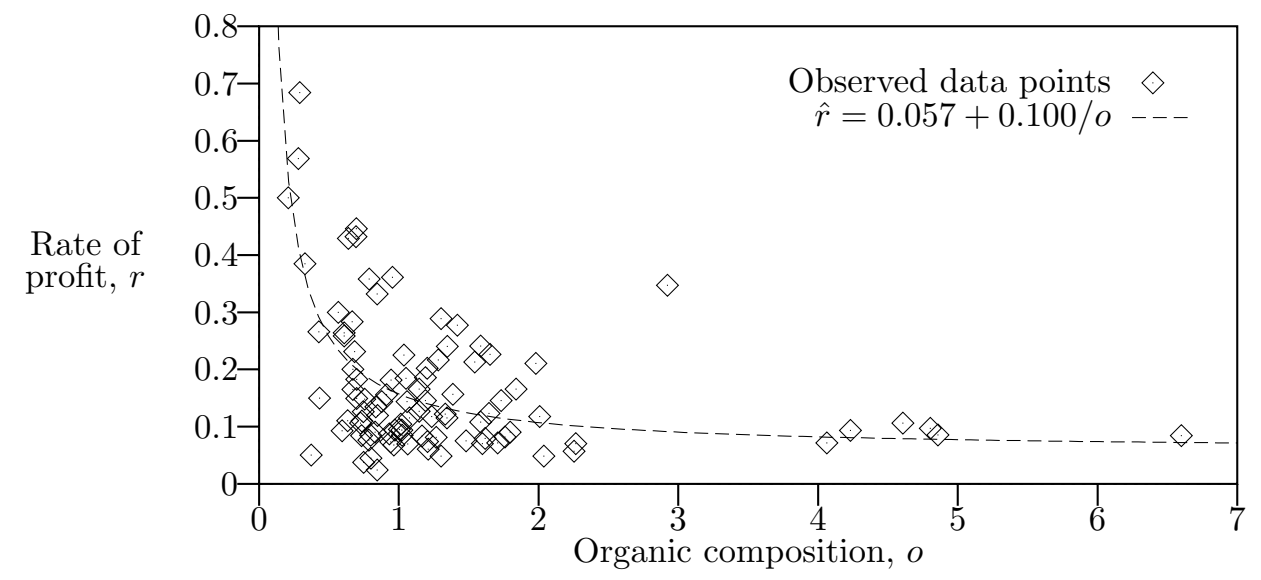

Figure 5: Organic composition versus rate of profit

Let us now turn to the simple labour theory of value. The first point to notice here is the support the theory receives from the observed narrow distributions of the price-value ratio and of the rate of surplus value. On the basis of very general statistical considerations, plus the assumption that 
there should be a very small probability (no more than $\frac{1}{1000}$ ) of a commodity selling for a price too low to cover the total wage-costs of producing it, Farjoun and Machover (1983, chapter 5) predict that the ratio of price to value should be distributed approximately normally, with a coefficient of variation of no more than $\frac{1}{6}$. From our data, it appears they were conservative: the coefficient of variation is closer to $\frac{1}{10}$.

On the other hand, from this point of view it may seem puzzling that the ratio of market prices to prices of production, $\phi$, has a considerably narrower distribution than that of the rate of profit. Why should prices of production function reasonably well as predictors of prices? This is comprehensible in terms of the fact that the rate of profit is considerably less than 1 . Since profits make up only about 20 percent of prices, a 50 percent variation in the rate of profit will produce a variation of prices of about 10 percent. Thus we would expect the coefficient of variation of $\phi$ to be about $\frac{1}{5}$ that of $r$. This is in fact what we observe from Table 2 .

In addition, the data seem to indicate that some partial equalisation of the rate of profit is going on. Note that by this we do not mean simply that the equalisation of the rate of profit is subject to random disturbance; rather, we mean that reality seems to fall roughly half way between the simple labour theory of value and the theory of prices of production-half way, that is, between Volumes I and III of Capital! Consider in this light some of the other entries in Table 3. There is a negative correlation between organic composition and profit rates: this is what would be predicted on the basis of the simple labour theory of value. But there is also a significant positive correlation between organic composition and the rate of surplus value (expressed in terms of money): this is predicted by the theory of prices of production. Thus, while there seems to be some tendency for capitals with higher than average organic composition to realise a higher money-rate of surplus value, this effect is not strong enough to 'compensate' fully for their higher proportion of constant capital. Essentially the same story emerges from the positive correlation between organic composition and the price-value ratio, $\psi$. The fact that there exists a positive correlation is consistent with the price of production theory; but, again, the correlation is not strong enough to validate the theory. It is not strong enough to eliminate the negative correlation (statistically significant at the .05 level) between organic composition and the ratio of price to price of production, $\phi$.

These points are summarised in Table 4, which displays the predictions of the labour theory of value and the theory of prices of production regarding the signs of the correlation coefficients involving the organic composition of 
capital, alongside the signs of the observed coefficients.

Table 4: Correlations with organic composition

$$
\text { LTV TPP }
$$

\begin{tabular}{cccc} 
Variable & Prediction & Prediction & Observed \\
\hline$o=C /(S+V)$ & 1 & 1 & 1 \\
$r=S /(C+V)$ & - & 0 & - \\
$s=S /(S+V)$ & 0 & + & + \\
$\phi=P / \Pi$ & - & 0 & - \\
$\psi=P / \Lambda$ & 0 & + & + \\
\hline
\end{tabular}

Taking the above results at face value, it appears that market prices behave under the influence of two competing attractors - values, and prices of production. How might we explain this? With regard to the pull exercised by simple labour values, there is clearly a close mathematical relationship between the dispersion of rates of surplus value and the dispersion of pricevalue ratios. These distributions are either both wide or both narrow. This observation suggests two possible sorts of causal mechanisms.

1. Suppose that for some as yet untheorised reason the simple labour theory of value - where labour input is measured in hours rather than indirectly as wages paid-holds. The narrow dispersions of $s$ and $\phi$ could then be an effect of the equalisation of wage rates between industries.

2. Alternatively there may be a mechanism that operates on the rate of surplus value directly, acting to limit its dispersion. One can conceive of three subprocesses that might work this way:

(a) High wage rates in an industry would provide an incentive for employers to improve productivity and thus restore the share of value going to capital. This would limit the degree to which workers could reduce the rate of surplus value through trade union struggle.

(b) On the other hand, a high profit share in an industry strengthens the bargaining position of workers. Workers are more willing to strike if they know their employers are exploiting them intensively, while it also costs the employers more to resist a strike. 
This would limit the degree to which employers could increase the rate of surplus value.

(c) If productivity-based wage bargaining were common this would tend to stabilise the wage share.

These factors would all tend to limit the dispersion of $s$, and hence also of $\phi$.

Finally it is possible that mechanisms (1) and (2) are both operative. Further empirical work would have to be done to determine which of these hypotheses is correct.

\section{Conclusion}

Our title poses the question of whether Marx needed to 'transform' from the simple labour theory of value to the theory of prices of production. Our results here suggest that the thinking that drove Marx in this direction does latch onto one aspect of the reality of capitalist economies. There seems to be some mechanism pulling prices above the prediction of the simple LTV in industries with high organic composition of capital. On the other hand, this 'transformation' is incomplete, and other aspects of reality are better accounted for by the simple LTV than the TPP.

It has been common among Marxian economists to regard the LTV as pertaining to a higher level of abstraction than the TPP; that is, the LTV in effect abstracts from differences in organic composition, while the TPP generates a set of 'modified values' taking these differences into account. This view of things has opened the way for some Sraffians to argue that the TPP is the primary and 'correct' theory, and the LTV is in a sense parasitic: the LTV is expected to hold as a tolerable empirical approximation only to the extent that (a) the TPP holds and (b) differences in organic composition are not very great (and/or the average rate of profit is low). Our results lead us to reject any such formulation. The LTV is a 'deeper' theory than the TPP, yet its predictions are just as close, if not closer, to the observed reality of capitalism. Through the stochastic mêlée of the market, the set of prices predicted by the LTV provides one pole of attraction, while the set of prices of production provides another.

Against the background of the apparently interminable debate over the transformation problem at a purely theoretical level, one is led to ask why it took so long for economists to carry out relevant empirical investigations. 
The debate was not subject to total ideological closure, in that the formulations arrived at via the Sraffian linear algebra are empirically testable, yet for a long time little or no testing was done. The necessary input-output data have been available for forty or more years, and the computer technology to process these data for thirty years, but empirical tests of the theories had to wait until the last decade. The practice of political economy has in this area fallen far short of scientific standards. It cannot be too strongly emphasised that theorising in the absence of empirical data leads only to arid speculation, which, in a domain like political economy, will be driven primarily by ideological pressures.

\section{References}

Central Statistical Office, Input-Output Tables for the United Kingdom 1984 (London: HMSO, 1988).

W. P. Cockshott, A. Cottrell and G. Michaelson, 'Testing Marx: Some New Results from UK Data', Capital and Class, no. 55 (1995) 103-29.

G. Duménil and D. Lévy, The Economics of the Profit Rate (Aldershot: Edward Elgar, 1993).

E. Farjoun and M. Machover, Laws of Chaos (London: Verso, 1983).

K. Marx, Capital, Volume III (Moscow: Progress Publishers, 1971).

E. M. Ochoa, 'Values, Prices, and Wage-Profit Curves in the US Economy', Cambridge Journal of Economics, 13 (1989) 413-29.

P. Petrovic, 'The Deviation of Production Prices from Labour Values: Some Methodology and Empirical Evidence', Cambridge Journal of Economics, 11 (1987) 197-210.

A. Shaikh, 'The Transformation from Marx to Sraffa', in A. Freeman and E. Mandel (eds) Ricardo, Marx, Sraffa (London: Verso, 1984).

I. Steedman, Marx After Sraffa (London: New Left Books, 1977).

I. Steedman, 'Natural Prices, Differential Profit Rates and the Classical Competitive Process', The Manchester School, 52 (1984) 123-40.

A. Valle Baeza, 'Correspondence Between Labor Values and Prices: A New Approach', Review of Radical Political Economics, 26 (1994) 57-66. 